NOTA DE PESQUISA

\title{
DIALÉTICA ENTRE A HUMANIDADE E O MEIO NATURAL: REFLEXÕES SOBRE A GAIA DE LOVELOCK
}

\section{André Geraldo Berezuk ${ }^{36}$}

Analisar, conjecturar, modelar ou calcular são ações para um primeiro passo de entendimento e compreensão de um determinado tema ou problema que nos aflige. $O$ passo seguinte constitui-se em refletir, ponderar, meditar sobre a análise, sobre a conjectura, sobre os modelos e seus cálculos, não somente com a intenção de melhorá-los e diminuir-lhes o seu grau de incerteza, como também para se posicionar epistemologica e filosoficamente sobre o tema proposto. Lovelock, em sua obra La Venganza de la Tierra: por qué la tierra está rebelándose y cómo podemos todavía salvar a la humanidad, versão castelhana do The Revenge of Gaia: why the earth is fighting back and how we can still save humanity (2006), não somente apresenta como também convoca o leitor a modificar o tradicional conceito antropocêntrico de humanidade, baseado na idéia de que o Ser Humano é o centro da Terra e do Universo, para um conceito no qual ele é parte do próprio planeta, do próprio complexo natural em que está inserido, visão essa mais caracterizada por povos com fortes laços com a natureza, como os de procedência indígena. Incluído nesse conceito, de que o Ser Humano é parte intrínseca da natureza, o autor inglês expõe o seu conceito de Gaia, no qual se reconheceu, no seio da comunidade acadêmica, como a Teoria de Gaia.

Gaia, segundo as palavras do autor, constitui-se como uma metáfora da Terra Viva, na qual o planeta se comporta como um sistema vivo e que se autorregula para possibilitar a vida das criaturas que em seu interior coabitam. Para haver essa relação de coexistência, as formas de vida devem respeitar os limites do planeta, ou da Gaia. A necessidade da metáfora de Gaia é fundamental porque a própria humanidade, arraigada em um conceito antropocêntrico de dominação, tem dificuldades sérias em conceber o planeta como um "receptáculo de vida" no qual possibilita a sua própria existência. Consciente ou inconscientemente, a espécie humana pressupõe o próprio lar como um local a ser explorado, subjugado, moldado e arrogantemente "administrado". Lovelock, portanto, desde a década de 1970, arquiteta a Teoria de Gaia, tentando inserir, nos meios de comunicação e na própria comunidade acadêmica, uma postura menos arrogante e mais sensata de pensarmos o próprio planeta.

${ }^{36}$ Docente do Curso de Geografia da Universidade Federal da Grande Dourados - Faculdade de Ciências Humanas - e-mail: andreberezuk@ufgd.edu.br 
Créditos devem ser dados a Lovelock, uma vez que em um período em que as condições naturais da própria Terra estão se modificando significativamente, com a observada tendência do planeta a um processo de aquecimento global e de mudanças significativas referentes às características climáticas globais, uma nova consciência do mundo e de como conviver com o próprio é necessária. Mesmo em um mundo onde as incertezas são cada vez mais vigentes, onde o debate científico é marcado pelo jogo de interesses e pela parcialidade, que acirra as próprias incertezas e onde as decisões raramente são unânimes, uma questão é verídica e sua necessidade não pode ser refutada: a raça humana precisa modificar a forma pela qual ela vê, concebe e age com relação a seu próprio habitat, pois a própria raça humana é, segundo as palavras do próprio Lovelock, numerosa demais, exigente demais para com os recursos naturais do próprio planeta, exageradamente displicente para com a utilização desses recursos, e notavelmente ignorante para compreender a própria vulnerabilidade e o quão perto se encontra de sua própria extinção. Citando a teoria lovelockiana, o ser humano não respeita a Gaia, é altamente intolerante no que diz respeito às mudanças em seu padrão de vida, age como um parasita, não reflete sobre a própria perpetuação da espécie, arrisca-se gradativamente mais a se auto aniquilar.

O autor defende a idéia de que o aquecimento global realmente está em vigor (visão também defendida pelo autor dessa resenha) e pergunta se a própria humanidade já não ultrapassou um ponto irreversível (turning point). Todavia, mesmo que a ala considerada "cética" esteja com a razão, e os dados do próprio IPCC (Intergovernmental Panel on Climatic Change) apresentarem discordâncias metodológicas que impossibilitem a prova do aquecimento global antropogênico, é constatado que, desde o início das medições climatológicas e das observações empíricas ao longo dos últimos duzentos anos, existe a tendência de subida gradativa das temperaturas. Além disso, verificou-se também que o grau de impacto ambiental da espécie humana torna-se, com o decorrer das décadas, cada vez maior, contribuindo com o aumento consubstancial da própria vulnerabilidade da espécie humana. Dessa maneira, uma nova forma de conceber e tratar o meio ambiente é fundamental e obrigatória, validando a Teoria de Gaia, com o objetivo de modificar o modo explorador-predador, reducionista e insustentável de visualizar o próprio mundo, fruto de aspirações e desejos da ciência provindo do período iluminista.

Estamos, portanto, segundo Lovelock, em uma corrida contra o tempo, diante de uma população que cresce constantemente, que necessita de víveres e que é irredutível com relação à alteração de seus níveis de qualidade de vida. Todos os povos almejam viver como os habitantes dos mais desenvolvidos países do mundo, o que não deixa de ser algo compreensível, mas impossível perante os próprios limites de Gaia. Desse modo, a obra explicita uma preocupação em escala mundial concernente a outros dois fatores de fundamental importância para a Humanidade: energia e alimentos. No que se refere ao primeiro fator, o autor clama a própria sociedade a uma revisão epistemológica e filosófica para com a utilização da energia atômica, que seria a fonte de energia mais abundante, que causaria menos impactos ambientais ao planeta, e que se constitui como uma fonte de energia mais segura que a própria sociedade supõe. Lovelock não nega que ela possui os seus riscos, entretanto, alega que os seus riscos foram, ao longo dos últimos cinquenta 
anos, superdimensionados por uma sociedade que se traumatizou historicamente com a energia atômica, devido a sua utilização para fins bélicos e devido aos acidentes nucleares nas usinas, em especial Chernobyl. Relata inclusive que as chamadas energias alternativas, como a energia eólica e os biocombustíveis são: pouco eficientes (no caso da éolica), necessitando de milhões de unidades de energia (moinhos) para conseguir a energia adequada a um país; ou causador de impactos ambientais gigantes (biocombustíveis), que consumiriam recursos naturais essenciais como a água e os solos de uma região os quais poderiam ser utilizados para a produção de alimentos. Fontes de energia como a energia solar, a mareomotriz e o hidrogênio constituem-se como promissoras fontes, porém necessitam de maior desenvolvimento tecnológico para seu aproveitamento, o que poderá vir a ocorrer em um prazo de vinte a quarenta anos, caso haja boa vontade dos órgãos públicos. Enfatizando, por sua vez, o segundo fator, que são os alimentos, Lovelock inclusive cogita o desenvolvimento de tecnologias que possibilitem a nutrição mundial através de alimentos sintéticos, que seriam formados basicamente por compostos mais simples como açúcares e aminoácidos. A alimentação tradicional, embasada em víveres tradicionais, seria utópica a um mundo com oito bilhões de pessoas, estando a própria capacidade do planeta seriamente ameaçada.

A própria humanidade esquece-se de um fator importante para a sua própria perpetuação: esquece-se de que ela vive em um planeta que a acolhe. Desse modo, o discurso social para com a natureza, totalmente voltado à própria pesquisa para a busca de novos meios de sobrevivência e perpetuação, deve levar em consideração, em primeiro lugar, a conservação da Terra e, em segundo lugar, as suas próprias necessidades. Mas o que se constitui como comum é o inverso: um discurso ambiental que foca a sociedade vindo em primeiro lugar, e o planeta sendo visto como um aspecto de discussão secundária. Lovelock, ao longo de sua obra, cita inúmeras vezes que uma hecatombe ambiental aniquilaria aos seres humanos e não ao planeta, no entanto, não é fácil para a própria sociedade libertar-se do sedutor discurso antropocêntrico.

Em sua obra, o autor também reprova a aplicabilidade real do conceito de desenvolvimento sustentável, analisando-a como dotada de uma maquiavélica faceta ainda voltada às aspirações antropocêntricas, desrespeitando, na prática, os limites naturais de Gaia. Ele prefere um outro termo para a idéia de desenvolvimento sustentável, denominado "retirada sustentável", em que os limites naturais do planeta seriam de fato mais observados, delimitados e obedecidos sem estar tão influenciado pelas regras do mercado. Além disso, o consumo, o desenvolvimento e o próprio crescimento demográfico seriam refletidos, remodelados, recriados e otimizados. Assim, a análise lovelockiana critica e ironiza o chamado desenvolvimento sustentável. Entretanto, o autor vai além, critica, ao longo da obra, o próprio movimento ambientalista, analisando a postura altamente política dos grupos ambientalistas, por ele chamados de "verdes", verdes que contraditoriamente carecem de aprofundização técnica e cujos muitos integrantes não sabem o que se constitui o próprio meio natural.

Segundo Lovelock, quem poderá ensinar, conscientizar, instruir os jovens revoltosos que não aceitam limites ou imposições em sua própria casa? Haverá tempo para que esses jovens possam aprender a viver em sua própria casa antes de serem despejados pela proprietária? Mas o tempo corre, os rebeldes 
estão cientes de sua passagem e não querem conceber mudanças e, mesmo que uma parcela sua queira mudar a própria postura, não saberiam como o fazer. Esses jovens vivem como viciados, inseridos em um estilo de vida utópico, no qual a proprietária da casa não somente reprova como não suporta. Sacrifícios significativos seriam necessários para que esses jovens selassem a paz com a proprietária. Esses sacrifícios estariam concentrados em uma modificação dos modos de produção, do próprio sistema de alimentação, da própria maneira filosófica de conceber o próprio lar, a própria reprodução, a própria vida. Eles estariam dispostos a aceitar os sacrifícios? Metaforicamente, esses jovens somos nós. Quanto tempo nos resta?

\section{REFERÊNCIAS BIBLIOGRÁFICAS}

LOVELOCK, J. La Venganza de la Tierra: la teoría de gaia y el futuro de la humanidad. (Tradução de Mar García Puig). Barcelona : Planeta, 2006. 249 p. 